\begin{tabular}{|c|c|c|}
\hline & Int.J.Curr.Microbiol.App.Sci (2021) 10(12): 450-463 & \\
\hline & $\begin{array}{l}\text { International Journal of Current Microbiology and Applied Sciences } \\
\text { ISSN: 2319-7706 Volume } 10 \text { Number } 12 \text { (2021) } \\
\text { Journal homepage: http://www.ijcmas.com }\end{array}$ & $\$ 0$ \\
\hline $\begin{array}{l}\text { EXCELLENT } \\
\text { PUBLISHERS }\end{array}$ & & whwr.j.jems som \\
\hline
\end{tabular}

Original Research Article

https://doi.org/10.20546/ijcmas.2021.1012.050

\title{
Species Distribution and Antifungal Susceptibilities of Candida Isolates Recovered from High Risk Neonates and Infants from Tertiary Care Hospital in Northern India
}

\author{
Sarver Jahan $^{1}$, Mohd Waseeque $\operatorname{Khan}^{2}$ and Nazish Fatima ${ }^{1}$ \\ ${ }^{1}$ Department of Microbiology, JNMC, AMU, Aligarh, India \\ ${ }^{2}$ Department of Paediatric, IIMSR, Lucknow, India \\ *Corresponding author
}

Keywords

Candida albicans,

non albicans

Candida (NAC),

high risk neonates

and infants

\section{Article Info}

Received:

11 November 2021

Accepted:

05 November 2021

Available Online:

10 December 2021
A B S T R A C T

In recent years, fungal infections have risen exponentially and are a cause of significant morbidity and mortality especially in high risk babies. Although Candida albicans remains the most common fungal isolate from neonatal candidemia, longitudinal studies have detected a shift towards non-albicans Candida (NAC) species. To study the species distribution and antifungal susceptibility pattern of candidiasis among high risk neonates and infants. Samples were collected aseptically from 128 high risk neonates and infants admitted in the NICU and HDU at JNMCH, Aligarh from February 2013 to October 2014. They were cultured and identified by standard microbiological techniques. Antifungal susceptibility testing (Disc diffusion and broth micro dilution-minimum inhibitory concentration (BMD-MIC) was performed and interpreted as per NCCLS (M27-A2) and CLSI guidelines. Of the 128 neonates and infants studied $89(69.5 \%)$ had septicaemia, $14(10.9 \%)$ had oral thrush and $12(9.4 \%)$ had urinary tract infections. In our study we found 39 cases from which 49 isolates of Candida were isolated from different specimen. Of the 39 candidiasis cases Candida albicans (59.2\%) was the most common species isolated while non albicans Candida (NAC) were $40.8 \%$ ( $C$. tropicalis $14.3 \%$, C. parapsilosis $12.2 \%$, C. guilliermondii $6.2 \%$, C. glabrata $4 \%, C$. krusei $2 \%$ and $C$. dubliniensis $2 \%$ ). Resistance to fluconazole, ketoconazole, clotrimazole was observed in $10.3 \%, 10.3 \%, 6.8 \%$ isolates of $C$. albicans respectively. Resistance to fluconazole, clotrimazole and amphotericin B was observed in 15\%, 20\%, 16.7\% isolates of NAC respectively. No resistance was observed against itraconazole and nystatin. The maximum mortality was found in patients with NAC infections (52.9\%) in comparison to $C$. albicans infection (31.8\%). There is a considerable increase in Candida infections especially with NAC in neonates and infants with more resistance towards antifungal drugs. 


\section{Introduction}

Candida is capable of causing infections in both immunocompetent as well as immunocompromised hosts but the incidence of candidiasis is more in immunecompromised individuals especially high risk babies neonates and infants $(1,2)$. The incidence of candidiasis has increased dramatically over the past three decades (3). In hospitalized neonates and infants, Candida has evolved as an important cause of life threatening invasive infections, particularly in very low birth weight (VLBW) infants (2). These babies regardless of birth weight, size or gestational age, have a greater than average chance of mortality or morbidity, especially up to one year of life. Importance of Candida species in nursery and intensive care units (ICUs) is increasingly being recognized $(2,4)$. Correct identification of clinical yeast isolates has become essential for optimal clinical management. Ever-increasing numbers of immunosuppressed patients, a widening range of recognized pathogens, and the discovery of resistance to antifungal drugs are contributing factors to this necessity (5).

Antifungal susceptibility testing is still in its infancy as compared to antibacterial susceptibility testing. Various methods like disc diffusion, agar dilution, broth dilution etc are widely used (6). The development of the National Committee for Clinical Laboratory Standards (NCCLS) reference method (M27A) for broth dilution method for antifungal susceptibility testing has been an important tool in standardizing susceptibility testing. More recently, addition of colorimetric dyes like Alamar blue to the microdilution procedure and use of $E$ test has resulted in increased consistency and reliability of results.

Infection due to NAC spp. is clinically indistinguishable from that caused by $C$. albicans, but are more resistant to routinely used antifungal drugs (7). Therefore prompt identification of infecting species along with in vitro antifungal susceptibility testing is very important for prevention of emergence and spread of drug resistant Candida spp (8). It has been suggested that emergence of Candida spp. other than C.albicans is mostly due to the selection of less susceptible species by the pressure of antifungal agents such as fluconazole.

The increased isolation rates of nonalbicans Candida species and a gradual shift in the antifungal susceptibility profile have underlined the need to monitor laboratory data for possible emergence of resistance and to select most appropriate antifungal agent for therapy.

Taking into consideration the above mentioned facts, the present study was undertaken to isolate and characterize the Candida species from the infections of neonates and infants and to study the antifungal susceptibility pattern of the isolates.

\section{Materials and Methods}

The present study was carried out in the Department of Microbiology J. N. Medical College, AMU, on 128 high risk neonates and infants admitted in the NICU and in the HDU of Department of Paediatrics, during the period of one and half years from 2013 to 2014. Various clinical specimens including blood, tracheobronchial aspirate, oral swab, ear swab, CSF and urine were collected.

Specimens like endotracheal aspirate, urine, oral swab etc., were subjected to direct microscopy by making a lactophenol cotton blue(LCB) mount and /or a Gram stained smear. The samples were inoculated on to Sabouraud's dextrose agar as the main isolation medium. For blood samples, Approximately 1 to $2 \mathrm{ml}$ of blood was 
collected under aseptic precautions and inoculated in biphasic brain heart infusion medium. The culture medium was incubated at $37^{\circ} \mathrm{C}$ for a week or longer if required. Subculture was done on third, fifth, and seventh day. All the Candida isolates were subjected to germ tube test using normal human serum. Colonies were identified up to the species level on the basis of colony characteristics, morphology on Corn meal agar, growth on Hi- CHROME Candida agar, carbohydrate fermentation, and assimilation patterns $(9,10)$.

The procedure followed was in accordance with the ethical standards of the responsible committee and informed written consent was taken prior to every procedure.

All the isolates were screened for antifungal susceptibility testing by the Disk Diffusion method modified by Chakrabarti et al., (11) using yeast nitrogen base-glucose (YNBG) agar. The antifungal agents tested were Amphotericin B, Nystatin, Ketoconazole, Clotrimazole, Fluconazole and Itraconazole (HiMedia Laboratories, Mumbai, India). The broth micro dilution-minimum inhibitory concentration (BMD-MIC) of the isolates was performed for the fluconazole, ketoconazole and amphotericin B using RPMI medium and MOPS buffer. MIC results were interpreted as per NCCLS (M27-A2) (12) guidelines. Isolates showing fluconazole MIC $\leq 8 \mu \mathrm{g} / \mathrm{ml}$ were regarded as susceptible, $16-32 \mu \mathrm{g} / \mathrm{ml}$ as dose-dependent susceptible and $\geq 64 \mu \mathrm{g} / \mathrm{ml}$ as resistant. The quality control test was performed by using the strains of Candida parapsilosis (ATCC 22019), Candida krusei (ATCC 6258) and Candida albicans (ATCC 90028).

\section{Statistical Methods}

The 'chi-square' test and the Student's ' $t$ ' test were used to compare the data. A ' $p$ ' value of $<0.05$ was taken as indicative of statistical significance, and a ' $p$ ' value of $<0.01$ was considered highly significant.

\section{Results and Discussion}

One hundred and twenty eight high risk neonates and infants were included in the study.

The maximum number of patients included had septicaemia in $89(69.5 \%)$ cases followed by oral thrush in $14(10.9 \%)$ cases and urinary tract infections in $12(9.4 \%)$ cases. Other presentation included in the study were chronic suppurative otitis media (CSOM) (3.9\%), pneumonia $(3.1 \%)$ and meningitis (3.1\%) (Fig 1).

It can be seen that out of a total of 128 patients, Candida could be isolated in 39 $(30.5 \%)$ cases (Table 1$)$.

The maximum number of Candida isolates were found from patients with septiceamia $(59.2 \%)$ followed by cases of oral thrush $(16.3 \%)$ and cases of urinary tract infections (14.3\%) (Table 2).

Candida albicans (59.2\%) was the most common species isolated from neonates and infants suffering from candidiasis while non albicans Candida were $40.8 \%$. In non albicans Candida, Candida tropicalis (14.3\%) was most frequently isolated spp. followed by Candida parapsilosis(12.2\%),Candida guilliermondii (6.2\%), Candida glabrata $(4 \%)$, Candida krusei (2\%) and Candida dubliniensis (2\%) (Table 3).

The most common specimen from which Candida was isolated included blood 29 $(59.2 \%)$ and oral swab $8(16.3 \%)$. The most common species of Candida isolated from almost all the specimen was Candida albicans followed by Candida tropicalis from the non 
albicans Candida group (Table 4). 41.4\% C.albicans and $58.6 \%$ non albicans Candida was isolated from blood sample.(Fig 2)

Table 5 shows that all the isolates were susceptible to nystatin and Itraconazole. Resistance was observed in $12.2 \%$ isolates to fluconazole and clotrimazole, $6.1 \%$ isolates to ketoconazole and $2 \%$ isolates to amphotericin B.

Table 6 shows that out of a total of 49 isolates, $87.8 \%$ isolates were sensitive to clotrimazole and fluconazole, $93.9 \%$ to ketoconazole, $98 \%$ to amphotericin B and $100 \%$ each to nystatin and itraconazole. Resistance to fluconazole was observed in $3(10.3 \%)$ isolates of $C$. albicans and $3(15 \%)$ of NAC isolates. Among NAC $14.3 \%$ of $C$. tropicalis and $100 \%$ of $C$. dubliniensis and $100 \%$ of C. krusei were fluconazole resistant. Resistance to clotrimazole was seen in $6.8 \%$ isolates of $C$. albicans and $20 \%$ of NAC. Among NAC $28.5 \%$ of $C$. tropicalis, $33.3 \%$ of $C$. guilliermondii, $100 \%$ of C. krusei were resistant to clotrimazole. Resistance to ketoconazole was observed in $10.3 \%$ isolates of C.albicans and none of the NAC. Resistance to amphotericin B was observed in $16.7 \%$ isolates of $C$. parapsilosis. No resistance was observed against itraconazole and nystatin.

It was observed that $3.4 \%$ isolates of $C$. albicans had MIC value of $32 \mu \mathrm{g} / \mathrm{ml} .6 .9 \%$ of C. albicans and $14.3 \%$ of C. tropicalis had a MIC value of $>32 \mu \mathrm{g} / \mathrm{ml}$ and $100 \%$ of C.dubliniensis had a MIC value of $64 \mu \mathrm{g} / \mathrm{ml}$. This showed that $6.9 \%$ isolates of Candida albicans were resistant to fluconazole and $1(3.4 \%)$ isolate was dose dependent sensitive, while $1(16.7 \%)$ isolate of $C$. tropicalis and $1(100 \%)$ isolate of C.dubliniensis were resistant to fluconazole. Overall $10.2 \%$ Candida spp. were resistant to fluconazole (Table 7). It was observed that 2 (6.9\%) isolates of C.albicans and 1(100\%) isolate of C.dubliniensis had MIC value of $>0.125 \mu \mathrm{g} /$ $\mathrm{ml}$ which showed that they were resistant to ketoconazole.6.1\% of Candida isolates were resistant to ketoconazole.(Table 8 )

It was observed that only $1(16.7 \%)$ isolate of amphotericin B had MIC $>1 \mu \mathrm{g} / \mathrm{ml}$ i.e. it was resistant while rest of $83.3 \%$ isolates were sensitive to amphotericin B.(Table 9)

A total of 128 children suffering from various clinical diseases, categorized into different predefined high risk groups were included in the study to determine the profile of Candida infections with respect to the predominant species, pathogenic characteristics and antifungal susceptibility analysis of the isolates in high risk neonates and infants.

The most commonly identified patient group in this study were neonates and infants with septicaemia $(69.6 \%)$, followed by patients with oral thrush $(10.9 \%)$, urinary tract infection $(9.4 \%)$. The other group included patient with pneumonia (3.1\%), meningitis $(3.1 \%)$ and ear infection $(3.9 \%)$. Thus, the study group compromised of a varied patient population with different clinical diagnosis.

Overall the rate of Candida isolation from various specimens in our study group was $30.5 \%$. C.albicans formed the largest group (59.2\%) of Candida species isolated in this study. Pfaller et al., (13) had reported 66\%, Altuncu E (14) 66\%, Belet N (15) 65.7\%, Ariff S (16) $55 \%$ of Candida albicans isolation in their respective studies. Indian studies which reported almost similar findings were S Narain (53.3\%)(17), Kaur R $(50 \%)(18)$. However, Kotwal A et al., noted a much higher prevalence of C.albicans $(78.1 \%)(19)$. However certain other Indian studies showed non albicans Candida species as the most frequently isolated species. S Shivprakashan (20), Goel N (21), R.J. 
Kothavade (22), Deorukhkar SC et al., (23), Deepak J. et al., (24) they showed C.tropicalis as the most frequently isolated species. This species variation may be due to the differences in empiric or prophylaxis practices.

The spectrum of candidiasis varies from country to country. Although C.albicans remains the most common isolated spp. from cases of candidemia in USA, Europe, and South America (Brazil), its prevalence is decreasing over the time and non albicans Candida spp. are increasing. The ARTEMIS Surveillance Study which was carried out over a period of 6.5 years (1997-2003) in 127 medical centers in 39 countries has shown an increase in the prevalence of Candida species like C. tropicalis (4.6\% in 1997 to $7.5 \%$ in 2003) and C. parapsilosis (4.2\% in 1997 to $7.3 \%$ in 2003) $(13,25)$. This particular surveillance study showed a 2 to 10-fold increase in the isolation rates of rare species like C. guillermondii, C. kefyr and C. rugosa.

Although $C$. albicans was the most commonly isolated species $(59.2 \%)$ in our study non albicans Candida (NAC) also substantially caused candidiasis. The next most common isolate, C. tropicalis formed $14.3 \%$ of the total isolates. Kontoyiannis et al., (26) and Ariff S (16) also observed $C$. tropicalis as the second most common Candida species after Candida albicans to cause candidiasis. S Narain (17), Gelotar P et al., (27), Kaur R (18), from India reported $23.3 \%, 36 \%$ and $40 \%$ of isolation rate of $C$. tropicalis respectively. C. tropicalis is becoming an increasingly frequent pathogen in NICU.

C. parapsilosis was the third common species isolated (12.2\%). In contrast to our study $C$. parapsilosis has been reported as the second most common spp. in neonates in many western studies. (15, 28, 29). Fairchild (30) and Kaufmann (1) have found $C$. glabrata as the most common emerging spp. Occurrence of $C$. glabrata sepsis was noted commonly in patients with significant higher gestational age and birth weight compared to sepsis with non glabrata spp. C. glabrata was the second most common NAC spp. isolated in the study conducted by Deorukhkar SC et al., (23). However, we found a much lower incidence of infection by $C$. glabrata $(4.1 \%)$. According to several investigators, the increase in the frequency of infections has paralleled the increased use of fluconazole in some hospitals. In a more recent study, however, investigators described the association between $C$. glabrata infection and amphotericin B use rather than fluconazole (31). Other less commonly isolated Candida spp., in order of frequency included $C$. guilliermondii (6.2\%), C. dubliniensis (2\%) and $C$. krusei (2\%).

Among the patients in whom Candida was isolated, the most common group was neonates and infants with septicaemia (59.2\%). The other major patients group with candidiasis included those with oral thrush (16.3\%), UTI (14.3\%), meningitis $(4.1 \%)$, ear infection $(4.1 \%)$, pneumonia $(2 \%)$. This is in agreement with the findings of Altuncu $\mathrm{E}$ et al., (14).

In the present work we studied the susceptibility pattern of various Candida isolates to six antifungal agents, which included Fluconazole, Ketoconazole, Clotrimazole, Itraconazole, Amphotericin B and Nystatin by disk diffusion method. Further, the MIC values of the Candida isolates were evaluated for fluconazole, ketoconazole and amphotericin $\mathrm{B}$ by microbroth dilution method. The susceptibility pattern of Candida isolates shows that $87.8 \%$ isolates were susceptible to fluconazole and clotrimazole, $93.9 \%$ isolates were susceptible to ketoconazole, $98 \%$ to amphotericin B and all the isolates (100\%) were susceptible to each nystatin and itraconazole. Resistance was 
observed in $12.2 \%$ isolates to fluconazole and clotrimazole, $6.1 \%$ isolates to ketoconazole and $2 \%$ isolates to amphotericin B. These findings are in agreement with a study conducted Xess et al., (32) who reported $11.7 \%$ resistance to fluconazole and Belet $\mathrm{N}$ et al., (15) (8.5\%). In contrast to our study Narang et al., (33) and Kotwal et al., (19) found a higher rate of fluconazole resistance (24\% and $26 \%$ respectively).

In this study we found more resistance to azole group of antifungal agents as compared to amphotericin B in Candida isolates similar to the study by Changdeo S. Aher (34). Azole resistance in Candida spp. is of concern because these drugs are frequently used as therapeutic alternatives to amphotericin B. Azole group of antifungal agents are preferred because they are easy to administer and are less nephrotoxic. In our study resistance to fluconazole was observed in $10.3 \%$ isolates of C. albicans. Similar susceptibility of C.albicans isolates was also reported by Mokaddas et al., (35), Fadda et al., (36) and M.W. Rizvi et al., (37). In India, there is a lack of multicentric studies regarding antifungal susceptibility pattern. However, there are few studies from different parts of the country which give some idea regarding the epidemiology of antifungal resistance among candidemia isolates. Recently azole resistance was seen more common in NAC spp. as compared to $C$. albicans, we also found a higher rate of fluconazole resistance among NAC (15\%) as compared to $C$. albicans (10\%). Deorukhkar et al., (23) also found a higher drug resistance among NAC isolates. Among C. tropicalis 1 (14.2\%) and 2 $(28.6 \%)$ isolates were fluconazole and clotrimazole resistant respectively. Fluconazole resistance was observed in $27.3 \%$ of NAC spp. $14.2 \%$ of C. tropicalis and $100 \%$ of C. dubliniensis and $100 \%$ of C. krusei.

Fluconazole (or Azole) resistance is predominantly the consequence of previous exposure to fluconazole (or other azoles), particularly repeated and long-term exposure (38).

Roildes et al., (28), from Greece reported that all the isolates were susceptible to AMB, and 97.5\% were susceptible to azoles. However, one of the three $C$. tropicalis isolates was found resistant to azoles. Rowen et al.,(39) reported that $7.5 \%$ of non-albicans Candida blood isolates were non susceptible to fluconazole. The very low rate of azole resistance in their study may be related to the treatment policy in use at their center i.e. no systemic or topical antifungal agents are used prophylactically, and their empiric use is restricted only to few cases.

Overall, $97.3 \%$ of the Candida BSIs isolates tested were susceptible to fluconazole, which further confirms the infrequent fluconazole resistance among $C$. albicans, $C$. parapsilosis, and $C$. tropicalis reported in a recent global survey (40). The increase in the rate of fluconazole resistance in C.tropicalis is of concern because this species is one of the most commonly isolated NAC spp. and fluconazole is the most common antifungal agent used for the treatment of various types of candidiasis (8). Oberoi $\mathrm{J} \mathrm{K}$ et al., (41), found $C$. tropicalis, as the most common species isolated and was 90.5 per cent susceptible to fluconazole, whereas $C$. parapsilosis and $C$. glabrata showed lower sensitivity rates of 66.1 and 60.8 per cent, respectively. Deepak J. et al., (24) found a significant proportion of $C$. tropicalis isolates were resistant to azoles especially fluconazole. 
Table.1 Prevalence of Candida infection among neonates and infants in the study group

\begin{tabular}{|c|c|c|}
\hline Isolate & No. of cases & \% \\
\hline Candida spp. isolated & 39 & 30.5 \\
\hline No Candida spp. isolated & 89 & 69.5 \\
\hline Total & 128 & 100 \\
\hline
\end{tabular}

$(\mathrm{n}=128)$

Table.2 Distribution of Candida isolates in relation to clinical diagnosis in neonates and infants with candidiasis.

\begin{tabular}{|c|c|c|c|c|}
\hline Clinical diagnosis & $\begin{array}{c}\text { No. of } \\
\text { patients }\end{array}$ & Sample & No. of isolates & $\%$ \\
\hline \multirow[t]{3}{*}{ Septicaemia } & \multirow[t]{3}{*}{25} & Blood(23) & \multirow[t]{3}{*}{29} & \multirow[t]{3}{*}{59.2} \\
\hline & & blood (3)+urine $(3) *$ & & \\
\hline & & blood(3)+oral swab(3)* & & \\
\hline Oral thrush & 5 & Oral swab & $5+3 *=8$ & 16.3 \\
\hline UTI & 4 & Urine & $4+3 *=7$ & 14.3 \\
\hline CSOM & 2 & Ear swab & 2 & 4.1 \\
\hline Meningitis & 2 & $\mathrm{CSF}$ & 2 & 4.1 \\
\hline Pneumonia & 1 & Endotracheal aspirate & 1 & 2 \\
\hline Total & 39 & & 49 & 100 \\
\hline
\end{tabular}

*3 urine and 3 oral swab Candida isolates were from septicaemia patients.

Table.3 Candida spp. isolated from patients in the study group

\begin{tabular}{|c|c|c|c|c|}
\hline \multicolumn{2}{|c|}{ Candida spp. } & \multirow{2}{*}{$\begin{array}{c}\text { No. of isolates } \\
29\end{array}$} & \multicolumn{2}{|c|}{$\%$} \\
\hline $\begin{array}{l}\text { Candida albicans } \\
\text { ( 29) }\end{array}$ & C.albicans & & \multicolumn{2}{|c|}{59.2} \\
\hline \multirow{6}{*}{$\begin{array}{l}\text { Nonalbicans Candida } \\
\text { (20) }\end{array}$} & C.tropicalis & 7 & 14.3 & \multirow[t]{6}{*}{40.8} \\
\hline & C.parapsilosis & 6 & 12.2 & \\
\hline & C.guilliermondii & 3 & 6.2 & \\
\hline & C.glabrata & 2 & 4.1 & \\
\hline & C.dubliniensis & 1 & 2 & \\
\hline & C.krusei & 1 & 2 & \\
\hline Total & & 49 & \multicolumn{2}{|c|}{100} \\
\hline
\end{tabular}


Table.4 Isolation of different Candida spp. from various specimens.

\begin{tabular}{|c|c|c|c|c|c|c|c|c|}
\hline \multirow[t]{2}{*}{ Specimen } & \multicolumn{7}{|c|}{ Species of Candida } & \multirow[t]{2}{*}{ Total } \\
\hline & 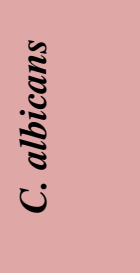 & 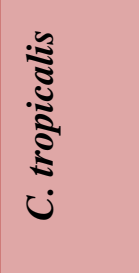 & 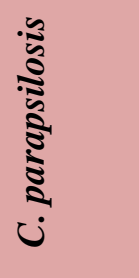 & 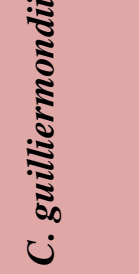 & 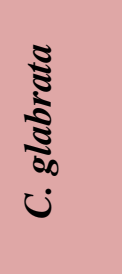 & 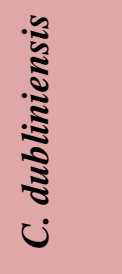 & ن & \\
\hline Blood & $12(41.4)$ & $5(17.2)$ & $5(17.2)$ & $3(10.3)$ & $2(6.9)$ & $1(3.4)$ & $1(3.4)$ & $29(59.2)$ \\
\hline Oral swab & $8(100)$ & - & - & - & - & - & - & $8(16.3)$ \\
\hline Urine & $5(71.4)$ & $1(14.3)$ & $1(14.3)$ & - & - & - & - & $7(14.3)$ \\
\hline Ear swab & $1(50)$ & $1(50)$ & - & - & - & - & - & $2(4.1)$ \\
\hline CSF & $2(50)$ & - & - & - & - & - & - & $2(4.1)$ \\
\hline Endotracheal aspirate & $1(100)$ & - & - & - & - & - & - & $1(2.0)$ \\
\hline Total & 29 & 7 & 6 & 3 & 2 & 1 & 1 & 49 \\
\hline
\end{tabular}

Figures in parenthesis indicate percentage

Table.5 Susceptibility pattern of Candida isolates to various antifungal agents by disc diffusion method

\begin{tabular}{|c|c|c|}
\hline Antifungal agent & Sensitive & Resistant \\
\hline Clotrimazole & $43(87.8)$ & $6(12.2)$ \\
\hline Fluconazole & $43(87.8)$ & $6(12.2)$ \\
\hline Amphotericin B & $48(98)$ & $1(2)$ \\
\hline Nystatin & $49(100)$ & 0 \\
\hline Ketoconazole & $46(93.9)$ & $3(6.1)$ \\
\hline Itraconazole & $49(100)$ & 0 \\
\hline
\end{tabular}

Figures in parenthesis indicate percentage

Fig.1 Distribution of patients in relation to the clinical diagnosis.

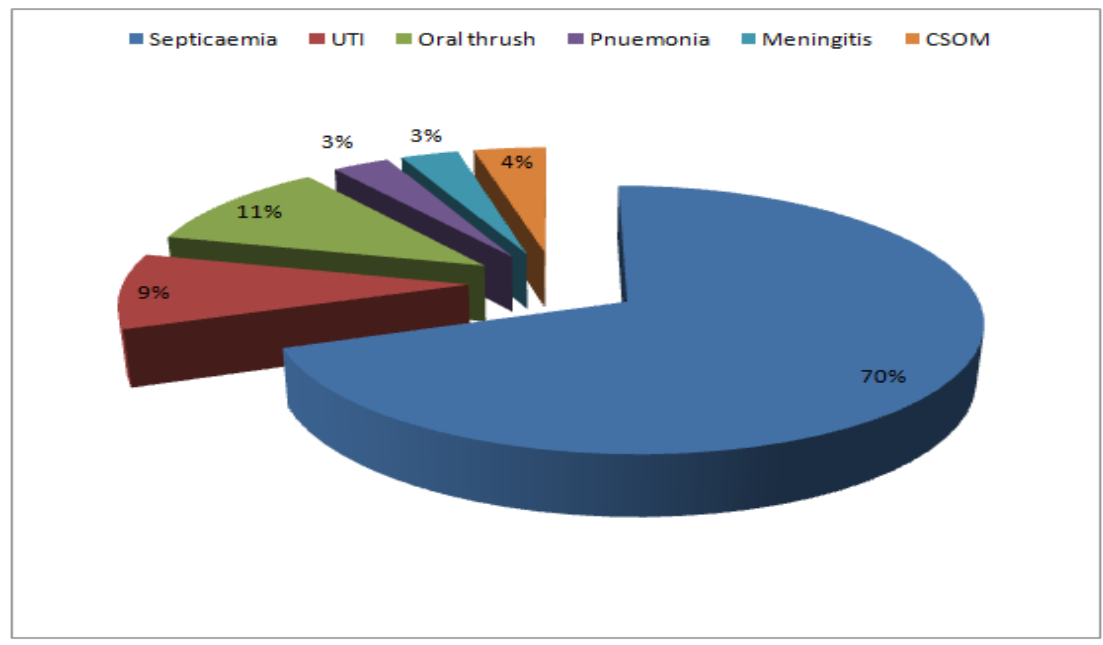


Table.6 Antifungal susceptibility pattern of various Candida spp. by disc diffusion method.

\begin{tabular}{|c|c|c|c|c|c|c|c|c|c|c|c|c|c|}
\hline \multirow[t]{2}{*}{ Candida spp. } & \multirow[t]{2}{*}{ 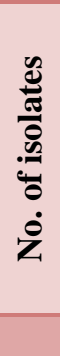 } & \multicolumn{2}{|l|}{ 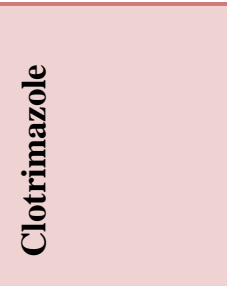 } & \multicolumn{2}{|l|}{ 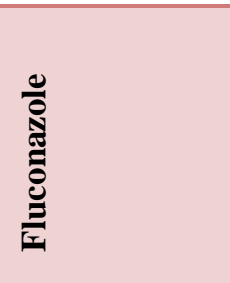 } & \multicolumn{2}{|l|}{ 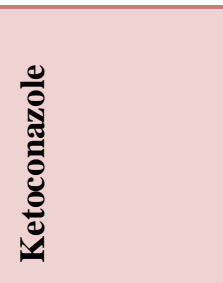 } & \multicolumn{2}{|l|}{ 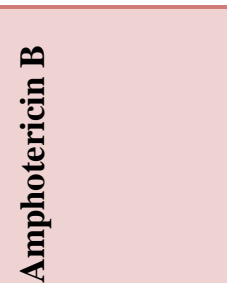 } & \multicolumn{2}{|l|}{ 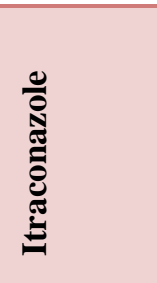 } & \multicolumn{2}{|l|}{ 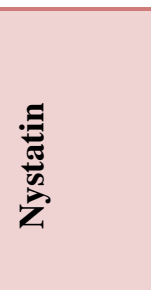 } \\
\hline & & S & $\mathrm{R}$ & S & $\mathrm{R}$ & S & $\mathrm{R}$ & S & $\mathrm{R}$ & S & $\mathrm{R}$ & S & $\mathrm{R}$ \\
\hline $\begin{array}{c}C . \\
\text { albicans }\end{array}$ & 29 & $\begin{array}{c}27 \\
(93.1)\end{array}$ & $\begin{array}{c}2 \\
(6.8)\end{array}$ & $\begin{array}{c}26 \\
(89.7)\end{array}$ & $\begin{array}{c}3 \\
(10.3)\end{array}$ & $\begin{array}{c}26 \\
(89.7)\end{array}$ & $\begin{array}{c}3 \\
(10.3)\end{array}$ & $\begin{array}{c}29 \\
(100)\end{array}$ & 0 & $\begin{array}{c}29 \\
(100)\end{array}$ & 0 & $\begin{array}{c}29 \\
(100)\end{array}$ & 0 \\
\hline $\begin{array}{c}C . \\
\text { tropicalis }\end{array}$ & 7 & $\begin{array}{c}5 \\
(71.4)\end{array}$ & $\begin{array}{c}2 \\
(28.6)\end{array}$ & $\begin{array}{c}6 \\
(85.7)\end{array}$ & $\begin{array}{c}1 \\
(14.3)\end{array}$ & $\begin{array}{c}7 \\
(100)\end{array}$ & 0 & $\begin{array}{c}7 \\
(100)\end{array}$ & 0 & $\begin{array}{c}7 \\
(100)\end{array}$ & 0 & $\begin{array}{c}7 \\
(100)\end{array}$ & 0 \\
\hline $\begin{array}{c}C . \\
\text { parapsilosis }\end{array}$ & 6 & $\begin{array}{c}6 \\
(100)\end{array}$ & 0 & $\begin{array}{c}6 \\
(100)\end{array}$ & 0 & $\begin{array}{c}6 \\
(100)\end{array}$ & 0 & $\begin{array}{c}5 \\
(83.3)\end{array}$ & $\begin{array}{c}1 \\
(16.7)\end{array}$ & $\begin{array}{c}6 \\
(100)\end{array}$ & 0 & $\begin{array}{c}6 \\
(100)\end{array}$ & 0 \\
\hline $\begin{array}{c}C . \\
\text { guilliermondii }\end{array}$ & 3 & $\begin{array}{c}2 \\
(66.7)\end{array}$ & $\begin{array}{c}1 \\
(33.3)\end{array}$ & $\begin{array}{c}3 \\
(100)\end{array}$ & 0 & $\begin{array}{c}3 \\
(100)\end{array}$ & 0 & $\begin{array}{c}3 \\
(100)\end{array}$ & 0 & $\begin{array}{c}3 \\
(100)\end{array}$ & 0 & $\begin{array}{c}3 \\
(100)\end{array}$ & 0 \\
\hline $\begin{array}{c}C . \\
\text { glabrata }\end{array}$ & 2 & $\begin{array}{c}2 \\
(100)\end{array}$ & 0 & $\begin{array}{c}2 \\
(100)\end{array}$ & 0 & $\begin{array}{c}2 \\
(100)\end{array}$ & 0 & $\begin{array}{c}2 \\
(100)\end{array}$ & 0 & $\begin{array}{c}2 \\
(100)\end{array}$ & 0 & $\begin{array}{c}2 \\
(100)\end{array}$ & 0 \\
\hline $\begin{array}{c}C . \\
\text { dubliniensis }\end{array}$ & 1 & $\begin{array}{c}1 \\
(100)\end{array}$ & 0 & 0 & $\begin{array}{c}1 \\
(100)\end{array}$ & $\begin{array}{c}1 \\
(100)\end{array}$ & 0 & $\begin{array}{c}1 \\
(100)\end{array}$ & 0 & $\begin{array}{c}1 \\
(100)\end{array}$ & 0 & $\begin{array}{c}1 \\
(100)\end{array}$ & 0 \\
\hline $\begin{array}{c}C . \\
\text { krusei }\end{array}$ & 1 & 0 & $\begin{array}{c}1 \\
(100)\end{array}$ & 0 & $\begin{array}{c}1 \\
(100)\end{array}$ & $\begin{array}{c}1 \\
(100)\end{array}$ & 0 & $\begin{array}{c}1 \\
(100)\end{array}$ & 0 & $\begin{array}{c}1 \\
(100)\end{array}$ & 0 & $\begin{array}{c}1 \\
(100)\end{array}$ & 0 \\
\hline Total & 49 & $\begin{array}{c}43 \\
(87.8)\end{array}$ & $\begin{array}{c}6 \\
(12.2)\end{array}$ & $\begin{array}{c}43 \\
(47.8)\end{array}$ & $\begin{array}{c}6 \\
(12.2)\end{array}$ & $\begin{array}{c}46 \\
(93.9)\end{array}$ & $\begin{array}{c}3 \\
(8.1)\end{array}$ & $\begin{array}{c}48 \\
(98)\end{array}$ & $\begin{array}{c}1 \\
(2)\end{array}$ & $\begin{array}{c}49 \\
(100)\end{array}$ & 0 & $\begin{array}{c}49 \\
(100)\end{array}$ & 0 \\
\hline
\end{tabular}

Figures in parenthesis indicate percentage

Table.7 MIC values for Fluconazole (Broth microdilution method)

\begin{tabular}{|c|c|c|c|c|c|c|c|c|c|}
\hline Candida spp. & \multicolumn{7}{|c|}{ MIC of fluconazole $(\boldsymbol{\mu g} / \mathbf{m l})$} & Total \\
\cline { 2 - 10 } & $\mathbf{0 . 5}$ & $\mathbf{1}$ & $\mathbf{2}$ & $\mathbf{4}$ & $\mathbf{8}$ & $\mathbf{1 6}$ & $\mathbf{3 2}$ & $\mathbf{2 6 4}$ & \\
\hline C. albicans & 26 & - & - & - & - & - & $1(3.4)$ & $2(6.9)$ & 29 \\
\hline C. tropicalis & 6 & - & - & - & - & - & - & $1(14.3)$ & 7 \\
\hline C. parapsilosis & 6 & - & - & - & - & - & - & - & 6 \\
\hline C. guilliermondii & 3 & - & - & - & - & - & - & - & 3 \\
\hline C. glabrata & 2 & - & - & - & - & - & - & - & 2 \\
\hline C. krusei & - & - & - & - & - & & - & $1(100)$ & 1 \\
\hline C. dubliniensis & - & - & - & - & - & - & - & $1(100)$ & 1 \\
\hline Total & $\mathbf{4 3}$ & - & - & - & - & - & $\mathbf{1}$ & $\mathbf{5}$ & $\mathbf{4 9}$ \\
\hline
\end{tabular}

Figures in parenthesis indicate percentage

$(\mathrm{S},<8 \mu \mathrm{g} / \mathrm{ml} ; \mathrm{S}-\mathrm{DD},>8 \mu \mathrm{g} / \mathrm{ml}$ and $\leq 32 \mu \mathrm{g} / \mathrm{ml} ; \mathrm{R},>32 \mu \mathrm{g} / \mathrm{ml})$ 
Table.8 MIC of ketoconazole (Broth microdilution method)

\begin{tabular}{|c|c|c|c|c|c|c|c|c|c|c|}
\hline \multirow{2}{*}{ Candida spp. } & \multicolumn{7}{|c|}{ MIC of ketoconazole $(\boldsymbol{\mu g} / \mathbf{m l})$} & \multirow{2}{*}{ Total } \\
\cline { 2 - 9 } & $\leq \mathbf{0 . 0 6}$ & $\mathbf{0 . 1 2 5}$ & $\mathbf{0 . 2 5}$ & $\mathbf{0 . 5}$ & $\mathbf{1}$ & $\mathbf{2}$ & $\mathbf{4}$ & $\mathbf{8}$ & $\mathbf{1 6}$ & \\
\hline C. albicans & 27 & - & $2(6.9 \%)$ & - & - & - & - & - & - & 29 \\
\hline C. tropicalis & 7 & - & - & - & - & - & - & - & - & 7 \\
\hline C. parapsilosis & 6 & - & - & - & - & - & - & - & - & 6 \\
\hline C. guilliermondii & 3 & - & - & - & - & - & - & - & - & 3 \\
\hline C. glabrata & 2 & - & - & - & - & - & - & - & - & 2 \\
\hline C. krusei & 1 & - & - & - & - & - & - & - & - & 1 \\
\hline C. dubliniensis & - & - & $1(100 \%)$ & - & - & - & - & - & - & 1 \\
\hline Total & $\mathbf{4 6}$ & - & $\mathbf{3 ( 6 . 1 \% )}$ & - & - & - & - & - & - & 49 \\
\hline
\end{tabular}

Figures in parenthesis indicate percentage

(MIC of $>0.125 \mu \mathrm{g} / \mathrm{ml}$ by M27- A are less likely to respond to ketoconazole)

Table.9 MIC of amphotericin B. (Broth microdilution method)

\begin{tabular}{|c|c|c|c|c|c|c|c|c|c|c|}
\hline \multirow[t]{2}{*}{ Candida spp. } & \multicolumn{9}{|c|}{$\begin{array}{c}\text { MIC of amphotericin B } \\
(\mu \mathrm{g} / \mathrm{ml})\end{array}$} & \multirow[t]{2}{*}{ Tota } \\
\hline & $\leq 0.06$ & 0.125 & 0.25 & 0.5 & 1 & 2 & 4 & 8 & 16 & \\
\hline C. albicans & 29 & - & - & - & - & - & - & - & - & 29 \\
\hline C. tropicalis & 7 & - & - & - & - & - & - & - & - & 7 \\
\hline C. parapsilosis & 5 & - & - & - & $\begin{array}{c}1 \\
(16.7 \%)\end{array}$ & - & - & - & - & 6 \\
\hline C.guilliermondii & 3 & - & - & - & - & - & - & - & - & 3 \\
\hline C. glabrata & 2 & - & - & - & - & - & - & - & - & 2 \\
\hline C. krusei & 1 & - & - & - & - & - & - & - & - & 1 \\
\hline C. dubliniensis & 1 & - & - & - & - & - & - & - & - & 1 \\
\hline Total & 48 & - & - & - & 1 & - & - & - & - & 49 \\
\hline
\end{tabular}

Figures in parenthesis indicate percentage

(MICs of $>1 \mu \mathrm{g} / \mathrm{ml}$ are probably resistant;M27-A)

Fig.2

\section{Blood samples}

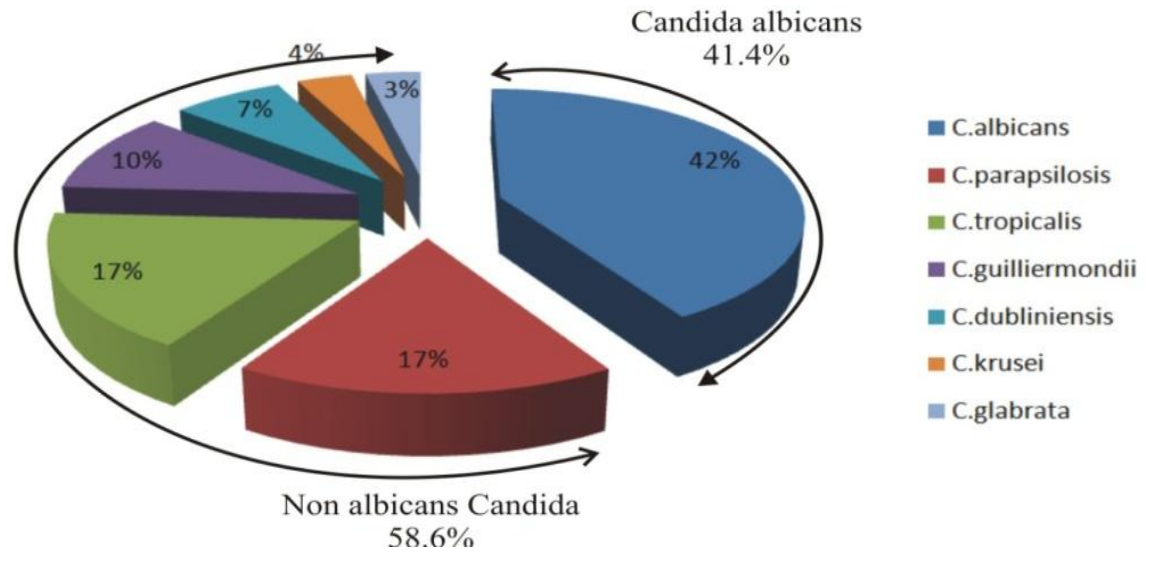


Strains of C. parasilosis, C. glabrata were sensitive to fluconazole 1 (16.6\%) $C$. parasilosis isolates was amphoterecin B resistant. In China, Ying Liang Yang et al., found that all $C$. parapsilosis isolates were sensitive to fluconazole and the C. krusei isolates had the highest resistance rate to fluconazole (42).

We found that C. glabrata was sensitive to all the drugs tested. High degree of resistance to azoles was seen among C. krusei (78.57\%) and C. glabrata $(63.16 \%)$ by Deepak J., et al., (24). Steinbach W.J. (43) found only $63 \%$ of C. glabrata isolates in children $<1$ year of age to be susceptible to fluconazole. Although resistance to AMB was quite low (3.79\%), but is a matter of concern as emergence of such isolates may pose serious therapeutic challenges and also increases risk of nosocomial infection. AMB constitutes the most preferred agent for the treatment of neonatal candidiasis (44).

In our study the results of susceptibity by disc diffusion method and with broth microdilution method were found to be almost same. $3.4 \%$ isolates of $C$. albicans had MIC value of 32 $\mu \mathrm{g} / \mathrm{ml} .6 .9 \%$ of $C$. albicans and $16.7 \%$ of $C$. tropicalis had a MIC value of $>32 \mu \mathrm{g} / \mathrm{ml}$ and $100 \%$ of C. dubliniensis had a MIC value of $64 \mu \mathrm{g} / \mathrm{ml}$. This showed that $6.9 \%$ isolates of Candida albicans were resistant to fluconazole and 1(3.4\%) isolate was dose dependent sensitive, while $1(16.7 \%)$ isolate of C. tropicalis and 1(100\%) isolate of $C$. dubliniensis were resistant to fluconazole. Pfaller et al., (45) have also reported similar MICs for fluconazole (32 to $128 \mu \mathrm{g} / \mathrm{ml}$ ). Colombo et al., (46) also reported MIC value of $>32 \mu \mathrm{g} / \mathrm{ml}$ for fluconazole. However, they reported a MIC range of 0.125 to $>32 \mu \mathrm{g} / \mathrm{ml}$.

Overall $10.2 \%$ Candida spp. were resistant to fluconazole by broth micro dilution method which was approximately same as by disc diffusion method $(12.2 \%)$, as isolate of C.albicans was dose dependent sensitive.

The results of susceptibility pattern of ketoconazole and amphotericin B were found to correlate with the findings of disc diffusion method. We did not find any resistance to itraconazole and nystatin. These findings were in accordance with Pfaller et al., (47).

The predominant Candida spp. causing candidaemia were the non albicans Candida (NAC) although Candida albicans were the overall predominant group in Candidiasis patient. Among the NAC Blood stream infection (BSI), C.tropicalis and $C$. parapsilosis were the common species isolated. Other NAC species causing BSI among neonates and infants were C.guilliermondii, C.glabrata, C.dubliniensis and C.kursei.

On studying the susceptibility pattern of various Candida isolates, we observed that all the isolates were sensitive to itraconazole and nystatin. Among individual species, the incidence of fluconazole resistance among C.albicans isolates was $10.3 \%$, while ketoconazole was $6.9 \%$ resistant, clotrimazole was $6.8 \%$ resistant. Among C.tropicalis, $1(14.2 \%)$ and $2(28.6 \%)$ isolates were fluconazole and clotrimazole resistant respectively. 1 (16.6\%) C.parasilosis isolate was amphoterician B resistant. C.glabrata was sensitive to all antifungal agents tested. $1(100 \%)$ isolate of C.dubliniensis was fluconazole resistant. 1(100\%) isolate of C.kursei was resistant to clotrimazole and fluconazole.

Candida is significantly rising. Non albicans candidiasis should be considered when initiating antifungal prophylaxis as they possess a different antifungal susceptibility spectrum from $C$. albicans. 
Therefore clinicians should strongly suspect Candida infection other than a bacterial infection in neonates and infants belonging to high risk group. Pediatricians should request for fungal culture and antifungal susceptibility testing before initiating antifungal prophylaxis.

\section{References}

1. Kaufman D, Fairchild K D. Clinical microbiology of bacterial and fungal sepsis in very-low-birth-weight infants. Clin Microbiol.2004; 17(3):638-80.

2. Ortega M., Marco F., Soriano A., Almela M., Martınez J. A., Lopez J., Pitart, C. \& Mens J. Candida species bloodstream infection: epidemiology and outcome in a single institution from 1991 to 2008.2011. J Hosp Infect 77, 157-161.

3. Enoch D A, Ludlam H A, Brown N M. Invasive fungal infections: a review of epidemiology and management options. J Med Microbiol 2006;55:809-818.

4. Stoll B J, Hansen N, Fanaroff A A et al., Late-onset sepsis in very low birth weight neonates: the experience of the NICHD Neonatal Research Network. Pediatrics. 2002; 110(1):285-291.

5. Nadeem S G, Hakim S T, Kazmi S U. Use of CHROMagar Candida for the presumptive identification of Candida species directly from clinical specimens in resource-limited settings. Libyan J Med 2010,5:2144

6. Chakrabarti A, Mohan B, Shrivastava S K, Marak R S, Ghosh A, Ray P. Change in distribution and antifungal susceptibility of Candida species isolated from candidaemia cases in a tertiary care centre during 19962000. Indian J Med Res 2002;116:5-12.

7. Johnson E M, Warnock D W. Azole drug resistance in yeasts.J Antimicrob Chemother. 1995 Nov;36(5):751-5

8. Deorukhkar S and Saini S. Non albicans Candida species: its isolation pattern, species distribution, virulence factors and antifungal susceptibility profile. International Journal of Medical Science and Public Health. 2013; 2 (3): 533-538.

9. Chander J. Text Book of Medical Mycology, 3rd edition. 2009; 20:274-279.

10. Mackie T J ; Collee J G; McCartney J E et al., Mackie and McCartney practical medical microbiology.2007; $14^{\text {th }}$ ed. Elsevier Publication.

11. Chakrabarti A, Ghosh A, Batra R, Kaushal A, Roy P, Singh H. Antifungal susceptibility pattern of non-albicans Candida species \& distribution of species isolated from Candidaemia cases over a 5 year period Indian J Med Res. 1996 Aug;104:171-6.

12. Reference method for broth dilution testing of yeast approved standard. 2nd ed. Wayne, PA: NCCLS; 2002. National Committee for Clinical Laboratory Standards. M.27-A2.

13. Pfaller $M$ A and Diekema D J. Epidemiology of invasive candidiasis: a persistent public health problem. Clin Microbiol Rev. 2007; 20:133-63.

14. Altuncu E, Bilgen $\mathrm{H}$, Cerikcioglu $\mathrm{N}$ et al., Neonatal Candida infections and the antifungal susceptibilities of the related Candida species. Mikrobiyol Bul. 2010; 44(4):593-603.

15. Belet N, Cifti E, Aysev D et al., Invasive Candida Infections in children:the clinical characteristics and species distribution and antifungal susceptibility of Candida spp. Turk J Pediatr. 2011; 53(5): 489-98.

16. Ariff S, Saleem A F, Soofi S B et al., Clinical spectrum and outcomes of neonatal candidiasis in a tertiary care hospital in Karachi, Pakistan. J Infect Dev Ctries. 2011; 5(3):216-223.

17. S Narain. Neonatal systemic candidiasis in a tertiary care centre. Indian journal of medical microbiology. 2003; 21 (1): 5658.

18. Kaur R, Goyal R, Dhakad M S et al., 
Epidemiology and Virulence Determinants including Biofilm Profile of Candida Infections in an ICU in a Tertiary Hospital in India. Journal of Mycology.2014 ;14Article ID 303491, 8 pages.

19. Kotwal A, Biswas D, Sharma J P, et al., An observational study on the epidemiological and mycological profile of Candidemia in ICU patients. Med Sci Monit. 2011; 17(11): 663-668.

20. Shivaprakasha S, Radhakrishnan $\mathrm{K}$ and Karim P. Candida spp. other than Candida albicans: a major cause of fungaemia in a tertiary care centre. Indian Journal of Medical Microbiology. 2007; 25 (4):405407.

21. Goel N, Ranjan P K, Agarwal R, Chaudhary U, Sanjeev N. Emergence of nonalbicans Candida in neonatal septicemia and antifungal susceptibility: Experience from a tertiary care centre. J Lab Physicians. 2009; 1:53-5.

22. Kothavade R J, Kura M M, Valand A G et al., Candida tropicalis: Its prevalence, pathogenicity and increasing resistance to fluconazole. J Med Microbiol. 2010; 59:873-80.

23. Deorukhkar S. C. and Saini S, "Species distribution and antifungal susceptibility profile of Candida species isolated from blood stream infections. Journal of Evolution of Medical and Dental Sciences. 2012 vol.1,no.3,pp.241-249.

24. Deepak J, Sharma M, Pal S. Emergence of Non-Albicans Candida Species in Neonatal Candidemia. North American Journal of Medical Sciences. 2013; 5(9):541-545.

25. Trick W E, Fridkin S K, Edwards J R, Hajjeh R A, Gaynes R P. Secular trend of hospital-acquired candidemia among intensive care unit patients in the United States during 1989-1999. Clin Infect Dis 2002; 35: 627-30.

26. Kontoyiannis D P, Vaziri I, Hanna H A et al., Risk factors for Candida tropicalis fungemia in patients with cancer. Clin Infect Dis. 2001; 33:1676-1681.

27. Gelotar P, Mundra N A, Sinha M et al., Candida infection in neonates. $\mathrm{J}$ pharma biomed sci.2012; vol 23 issue 23.

28. Roilides E, Farmaki E, Evdoridou J et al., Neonatal candidiasis: analysis of epidemiology, drug susceptibility, and molecular typing of causative isolates. Eur J Clin Microbiol Infect Dis. 2004; 23: 745-750.

29. Pires, R. H., Santos, J. M., Zaia, J. E., Martins, C. H. G. \& Mendes Giannini, M. J. Candida parapsilosis complex water isolates from a haemodialysis unit: biofilm production and in vitro evaluation of the use of clinical antifungals. Mem Inst Oswaldo Cruz (2011a)106, 646-654.

30. Fairchild K D, Tomkoria S, Sharp E C, Mena F V. Neonatal Candida glabrata sepsis: clinical and laboratory features compared with other Candida species. Pediatr Infect Dis J. 2002 Jan;21(1):39-43.

31. Fidel, P. L., Vazquez, J. A. \& Sobel, J. D. Candida glabrata: Review of epidemiology, pathogenesis and clinical disease with comparison to $C$. albicans. Clin Microbiol Rev.1999; 12, 80-96.

32. Xess I, Jain N, Hasan F, Mandal P, Banerjee U. Epidemiology of candidemia in a tertiary care centre of North India: 5Year Study. Infection 2007;35:256-9.

33. Narang A, Agarwal P R, Chakrabarti A et al., Epidemiology of systemic candidiasis in a tertiary care neonatal unit. J Trop pediatrics. 1998; 44(2):104-108.

34. Changdeo S. Aher, Species ditribution, virulence factors and antifungal susceptibility profile of Candida isolated from Oropharyngeal lesions HIV infected paients.Int. J Cur Micobl. Ap Sci. 2014; 3(1): 453-460.

35. Mokaddas E M, Al-Sweih N A, Khan Z U. Species distribution and antifungal susceptibility of Candida bloodstream isolates in Kuwait: a 10-year study. 
Journal of Medical Microbiology. 2007;56 (2): 255-259.

36. Fadda M E, Podda G S, Pisano M B et al., Prevalence of Candida species in different hospital wards and their susceptibility to antifungal agents: results of a three year survey. Journal of Preventive Medicine and Hygiene.2008; 49 (2): 69-74.

37. Rizvi M W, Malik A, Shahid M et al., Candida albicans in north Indian tertiary care: antifungal resistance pattern and role of SDS-PAGE for characterization. Biology and Medicine. 2011; 3(2):176181.

38. Rex J H, Rinaldi M G, Pfaller M A. Resistance of Candida species to fluconazole. Antimicrob Agents Chemother. 1995 Jan;39(1):1-8.

39. Rowen J L, Tate J M, Nordoff $\mathrm{N}$ et al., Candida isolates from neonates: frequency of mis- identification and reduced fluconazole susceptibility. J Clin Microbiol. 1999; 37:3735-3737.

40. Pfaller M A, Diekema D J, Gibbs D L et al., Results from the ARTEMIS DISK Global Antifungal Surveillance Study, 1997 to 2007: a 10.5-year analysis of susceptibilities of Candida species to fluconazole and voriconazole as determined by CLSI standardized disk diffusion. J. Clin. Microbiol. 2010 ;
48:1366-1377.

41. Oberoi J K, Wattal C, Goel N et al., Nonalbicans Candida species in blood stream infections in a tertiary care hospital at New Delhi, India. Indian J Med Res. 2012; $997-$ 1003.

42. Yang Y L, Li S Y, Cheng $\mathrm{H} H$ et al., Susceptibilities to amphotericin B and fluconazole of Candida species in TSARY 2002. BMC Infect Dis. 2002 Nov 3;5:99.

43. Steinbach W J. Epidemiology of invasive fungal infections in neonates and children. Clin. Microbiol Infect. 2010; 16:13211327.

44. Rowen J L and Tate J M. Management of neonatal candidiasis. Neonatal Candidiasis Study Group. Pediatr Infect Dis.1998; 17:1007-1011.

45. Pfaller M A, Messer S A, Boyken L, Tendolkar $\mathrm{S}$ et al., Variation in susceptibility of bloodstream isolates of Candida glabrata to fluconazole according to patient age and geographic location. J. Clin. Microbiol.2003; 41:2176-2179.

46. Colombo A L, Guimarães T. Epidemiology of hematogenous infections due to Candida spp. Rev Soc Bras Med Trop. 2003; 36: 599-607.

47. Pfaller M A. Epidemiology of candidiasis. J Hosp Infect 30 (Suppl.) 1995: 329-338.

\section{How to cite this article:}

Sarver Jahan, Mohd Waseeque Khan and Nazish Fatima. 2021. Species Distribution and Antifungal Susceptibilities of Candida Isolates Recovered from High Risk Neonates and Infants from Tertiary Care Hospital in Northern India. Int.J.Curr.Microbiol.App.Sci. 10(12): 450-463. doi: https://doi.org/10.20546/ijcmas.2021.1012.050 